\title{
CONTAGEM DE CÉLULAS SOMÁTICAS EM VACAS DA RAÇA HOLANDESA E MESTIÇAS HOLANDÊS X JERSEY
}

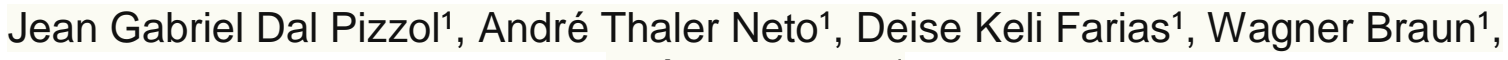 \\ Daíse Werncke ${ }^{1}$ \\ 1 UDESC \\ Correspondência: André Thaler Neto: thaler@cav.udesc.br
}

RESUMO: O cruzamento com a raça Jersey vem sendo utilizado principalmente como alternativa para o aumento da concentração de sólidos do leite em rebanhos da raça Holandesa. A mastite é uma das principais causas de descarte em rebanhos leiteiros e de perda de qualidade do leite. A Contagem de Células Somáticas no leite (CCS) é um indicativo de mastite subclínica, e possui diferença quanto sua apresentação nas raças, sendo esta a motivação do presente trabalho, cujo objetivo foi avaliar a contagem de células somáticas no leite de vacas mestiças Holandês $\mathrm{x}$ Jersey $\mathrm{e}$ de vacas puras da raça Holandesa. Os dados foram obtidos de uma propriedade localizada no município de Carambeí-PR, a qual possui vacas puras da raça Holandesa e mestiças Holandês $x$ Jersey em diferentes proporções de cada raça. Foram utilizados dados de Contagem de Células Somáticas (CCS) obtidos do controle leiteiro oficial, no período de 2005 a 2010. Os dados de CCS foram transformados para Escore de Células Somáticas (ECS) e submetidos à análise de variância através de medidas repetidas no tempo. Vacas mestiças adultas (a partir de 3 anos de idade no momento do parto), apresentaram menor ECS ( $\mathrm{P}<0,0001)$. Conclui-se que vacas mestiças adultas apresentam menor escore de células somáticas (ECS) em relação a vacas adultas da raça Holandesa.

Palavras-chave: cruzamento; mastite subclínica; qualidade do leite; raças leiteiras

\section{SOMATIC CELL COUNT IN HOLSTEIN AND CROSSBRED HOLSTEIN X JERSEY COWS}

\begin{abstract}
The crossbreeding with the Jersey breed has been used mainly as an alternative to increasing the concentration of milk solids in Holstein herds. Mastitis is a major cause of culling in dairy herds and the loss of milk quality. The somatic cell count in milk (CCS) is an indicator of subclinical mastitis, and has difference in your presentation in breeds, which is the motivation of this study, whose aim was to evaluate the somatic cell count in milk of crossbred Holstein $x$ Jersey cows and pure Holstein. Data were obtained from a herd located in the municipality of Carambeí-PR, which has pure Holstein cows and crossbred Holstein $\mathrm{x}$ Jersey in different proportions of each breed. Somatic Cell Count (SCC) data were obtained from the official milk control in the period of 20052010. The SCC data were transformed to somatic cell score (SCS) and subjected to analysis of variance using repeated measures. Adult crossbred cows (from 3 years old at the time of calving), had lower ECS $(\mathrm{P}<0.0001)$. It was concluded that adult crossbred cows have lower somatic cell score (SCS) in relation to adult Holstein cows.
\end{abstract}

Key Words: crossbreeding; milk quality; dairy breeds; subclinical mastitis 


\section{INTRODUÇÃO}

A sanidade da glândula mamária é um dos principais objetivos do manejo sanitário de bovinos leiteiros, visto que infecções na glândula mamária são patologias frequentemente encontradas nesta atividade e causam impacto econômico negativo para produtores e laticínios (Koeck et al., 2012). A mastite é um processo inflamatório da glândula mamária, acompanhado da redução de secreção de leite e mudança de permeabilidade da membrana que separa o leite do sangue, cujo impacto econômico está relacionado à produção de leite, gastos com tratamento, descarte de leite e de animais, aumento de mão de obra e diminuição do valor econômico dos animais (Pereira et al., 2001).

Não existem muitas evidências científicas quanto às diferenças na resistência à mastite entre as raças Holandesa e Jersey. Alguns trabalhos evidenciam que, aparentemente, os mecanismos de defesa são semelhantes para estas duas raças, como por exemplo, nos casos de infecções causadas tanto por Staphylococcus aureus (Bannerman et al., 2008b), como por Escherichia coli (Bannerman et al., 2008a). Trabalhos no Canadá e nos Estados Unidos demonstraram que, apesar da raça Jersey apresentar contagem de células somáticas levemente superior à da raça Holandesa, o risco de descarte por mastite foi semelhante nestas duas raças (Caraviello et al., 2005; Sewalem et al., 2006).

Existem poucos trabalhos sobre a CCS em vacas mestiças. Ao comparar vacas mestiças Holandês $x$ Jersey $e$ vacas puras da raça Holandesa, nas três primeiras lactações, Heins et al. (2009) não encontraram diferença significativa na contagem de células somáticas nas duas primeiras lactações entre os dois grupamentos genéticos.
Porém, na terceira lactação, as vacas cruzadas tenderam $(P<0,10)$ a ter contagem de células somáticas mais elevada do que as vacas puras. Em um levantamento comparando rebanhos na Nova Zelândia que possuíam animais mestiços Holandês x Jersey e puros da raça Holandesa (Clunyexports, 2008), apontaram valores médios mais baixos de contagem de células somáticas nos animais mestiços. Prendiville et al. (2010), avaliando vacas da raça Holandesa, Jersey e $F_{1}$ Holandês $x$ Jersey em pastejo em um único rebanho, não encontraram diferenças estatísticas na contagem de células somáticas.

No Brasil, o uso do cruzamento entre a raça Holandesa e a raça Jersey é uma estratégia de manejo recente, sendo escassas as informações científicas a respeito de tal cruzamento. Nesse sentido, o objetivo do presente trabalho foi avaliar a contagem de células somáticas em vacas mestiças Holandês $X$ Jersey e vacas puras da raça Holandesa.

\section{MATERIAL E MÉTODOS}

Foram analisados dados de Contagem de Células Somáticas (CCS), oriundos do controle leiteiro oficial, no período de 2005 a 2010, provenientes de uma propriedade da cidade de Carambeí - PR. Os dados foram disponibilizados pelo Programa de Análises de Rebanhos Leiteiros do Paraná (PARLPR), da Associação Paranaense de Criadores de Bovinos da Raça Holandesa (APCBRH). A propriedade possuía sistema de produção baseado em pastejo com suplementação de volumoso e concentrado, com bom sistema de manejo com ordenha mecânica. O rebanho era constituído por animais da raça Holandesa e oriundos de cruzamento Holandês $x$ Jersey de diversas frações genéticas. As fêmeas 
mestiças Holandês $x$ Jersey foram geradas a partir de um programa de cruzamento com utilização de sêmen importado de touros provados da raça Jersey em rebanho originalmente composto por vacas puras de origem (PO) da raça Holandesa. Os animais foram divididos em dois grupos genéticos, sendo um grupo de vacas puras da raça Holandesa e outro composto de vacas mestiças $F_{1}$ Holandês x Jersey.

Foram analisados 2545 controles leiteiros de vacas paridas no período de 2005 a 2010, perfazendo 304 lactações de 124 vacas, sendo 55 puras da raça Holandesa e $69 F_{1}$ Holandês $x$ Jersey, com estágio de lactação entre 7 e 305 dias e idade ao parto entre 2 e 8 anos. Visando obter normalidade dos resíduos, foi realizada a transformação matemática da Contagem de Células Somáticas (CCS) para Escore de Células Somáticas (ECS), conforme definido por Teixeira et al. (2003):

$E C S=\log _{2}(C C S / 100.000)+3$

Os dados foram submetidos à análise de variância com medidas repetidas no tempo, utilizando-se 0 procedimento MIXED do pacote estatístico SAS. Foram analisados os efeitos das variáveis explanatórias grupo genético (Holandês e $1 / 2$ Holandês $x$ Jersey), ano e estação de parto, mês de lactação e sua interação com o grupo genético, idade ao parto e sua interação com o grupo genético e da covariável produção de leite.

\section{RESULTADOS E DISCUSSÃO}

A produção média de leite \pm erropadrão as vacas $F_{1}$ Holandês $x$ Jersey $e$

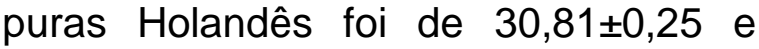
$33,24 \pm 0,29 \mathrm{~kg} / \mathrm{dia}$, respectivamente, sendo o ECS mais baixo nas vacas $F_{1}$ em relação às puras Holandês (Tabela 1). Estes resultados diferem dos obtidos por Heins et al. (2011) nos Estados
Unidos e Prendiville et al. (2010), os quais não observaram diferença de ECS em vacas mestiças e da raça Holandesa. Entretanto, os resultados estão de acordo com levantamentos de campo realizado em rebanhos na Nova Zelândia, os quais apontaram valores médios mais baixos para contagem de células somáticas em vacas mestiças Holandês x Jersey (CLUNYEXPORTS, 2008).

\begin{tabular}{|c|c|c|c|c|}
\hline $\begin{array}{l}\text { G rupamento } \\
\text { G enético }\end{array}$ & $\begin{array}{c}\text { Número de } \\
\text { Vacas }\end{array}$ & $\begin{array}{l}\text { Número de } \\
\text { Lactaçôes }\end{array}$ & $\begin{array}{l}\text { Número de } \\
\text { Controles }\end{array}$ & EC S\#्EPM* \\
\hline Holandês & 55 & 122 & 1029 & $3,74 \pm 0,07$ \\
\hline$F_{1}$ & 69 & 182 & 1516 & $2,84 \pm 0,06$ \\
\hline
\end{tabular}

Houve interação entre 0 grupamento genético e a idade da vaca ao parto. Observa-se na Figura 1 que vacas mestiças superam as vacas puras Holandês somente a partir de 3 anos de idade, não havendo diferença em vacas jovens. As diferenças altamente significativas a partir desta idade $(P<$ 0,0001 ) podem trazer ganhos em longevidade, visto que a mastite é uma das principais causas de descarte em bovinos de leite. Segundo dados do Departamento de Agricultura dos Estados Unidos, (ARS/USDA., 2009) cerca de $16,5 \%$ dos descartes de vacas no ano de 2006, nos Estados Unidos, foram em decorrência de mastite.

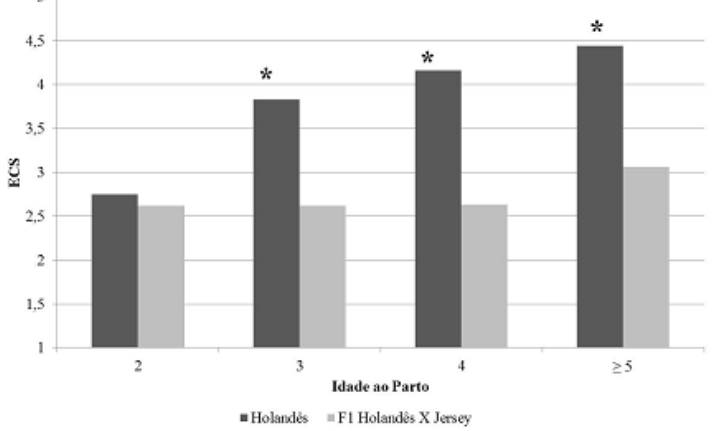

Figura 1 - Escore de Células Somáticas (ECS) em função da idade ao parto em vacas puras Holandês e $F_{1}$ Holandês x Jersey. (*grupamentos genéticos diferem significativamente a $5 \%$.

O aumento do ECS em função do aumento da idade ao parto também foi observado por Teixeira et al. (2003) em 
vacas da raça Holandesa, no Brasil, sendo o aumento atribuído possivelmente a maior oportunidade a exposição de agentes causadores de mastite e pelo prolongamento dos quadros de infecção. Resultados semelhantes foram observados por Cunha et al. (2008), analisando dados de controle leiteiro oficial no Estado de Minas Gerais.

Não foi observada interação entre - grupo genético e o estágio de lactação, sendo que, em ambos os grupamentos, os valores de ECS foram maiores ao final da lactação (Figura 2). Aumento no ECS no decorrer da lactação também foi observado por Prendiville et al. (2010), apesar de que em seu trabalho, o ECS nos animais mestiços não diferiram estatisticamente das vacas puras da raça Holandesa. Andrade et al. (2004), avaliando controles leiteiros de vacas da raça Holandesa nos anos de 1999 a 2002, também encontraram aumento na contagem de células somáticas com o avanço da fase de lactação.

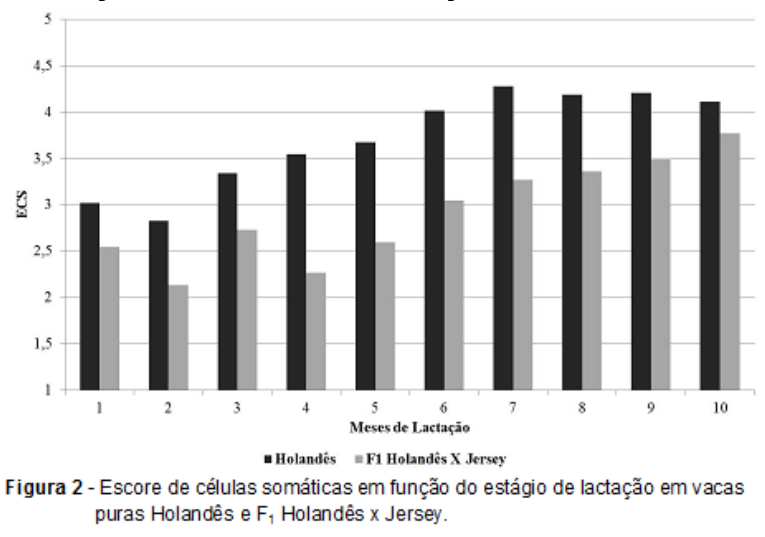

A variável produção de leite, estação e ano do controle leiteiro também afetaram o ECS $(P<0,01)$. Vacas com produção de leite mais elevada apresentaram menor ECS. Este resultado está de acordo com diversos trabalhos, tais como os de Coldebella et al. (2003) e Cunha et al. (2008) no Brasil, os quais demonstram redução na produção de leite em função do aumento na CCS. $\mathrm{Na}$ Suécia,
Hagnestam-Nielsen et al. (2009), observaram que vacas com 500.000 células $/ \mathrm{ml}$ apresentavam perdas na produção de leite, variando de 0,7 a 2,0 $\mathrm{kg}$ (3 a 9\%) em vacas primíparas e de 1,1 a $3,7 \mathrm{~kg}$ (4 to $18 \%$ ) em multíparas, dependendo do estágio de lactação. Segundo Jamrozik e Schaeffer (2012), o fato de vacas com menor produção de leite normalmente apresentarem maior CCS pode superestimar o efeito da CCS sobre a produção de leite.

Os resultados do presente estudo indicam a possibilidade de utilização do cruzamento com a raça Jersey como alternativa para rebanhos da raça Holandesa que apresentam elevada prevalência de mastite subclínica.

\section{CONCLUSÃO}

Vacas mestiças adultas apresentam menor escore de células somáticas (ECS) em relação a vacas adultas da raça Holandesa, sendo uma alternativa para 0 incremento da rentabilidade em sistemas de pagamento por qualidade e diminuindo os custos de produção.

\section{AGRADECIMENTOS}

À Granja RAG, nas pessoas dos senhores Raul e Ricardo Guimarães e à Associação Paranaense de Criadores de Bovinos da Raça Holandesa (APCBRH) por disponibilizar os dados para a realização deste estudo.

\section{REFERÊNCIAS}

ANDRADE, L.M.; EL FARO, L.;

ALBUQUERQUE, L.G. et al. Influência da contagem de células somáticas sobre a produção de leite em diferentes fases da lactação. V Simpósio da Sociedade Brasileira de melhoramento animal. Pirassununga - SP 2004.

ARS/USDA. Trait means for base cows.

ARS/USDA. 2009. 
BANNERMAN, D.D.; KAUF, A.C.; PAAPE, M.J. et al. Comparison of Holstein and Jersey innate immune responses to Escherichia coli intramammary infection. Journal of Dairy Science, v.91, n.6, p.2225-2235, 2008a.

BANNERMAN, D.D.; SPRINGER, H.R.; PAAPE, M.J. et al. Evaluation of breed-dependent differences in the innate immune responses of Holstein and Jersey cows to Staphylococcus aureus intramammary infection. Journal of Dairy Science, v.75, p.291-301, 2008b.

CARAVIELLO, D.Z.; WEIGEL, K.A.; SHOOK, G.E.; RUEGG, P.L. Assessment of the impact of somatic cell count on functional longevity in Holstein and Jersey cattle using survival analysis methodology. Journal of Dairy Science, v.88, n.2, p.804-811, 2005.

CLUNYEXPORTS. Crossbreeding HolsteinFriesian x Jersey Cattle Clunyexports Agrobusiness Specialists. 2008. Disponível em $<$ http://www.clunyexports.com.au/media/crossbr eedjhfJv11.pdf>.

COLDEBELLA, A.; MACHADO, P.F.; DEMÉTRIO, C.G.B. et al. Contagem de células somáticas e produção de leite em vacas holandesas de alta produção. Pesquisa Agropecuária Brasileira, v.38, n.12, p.14511457, 2003.

CUNHA, R.P.L.; MOLINA, L.R.; CARVALHO, A.U. et al. Mastite subclínica e relação da contagem de células somáticas com número de lactações, produção e composição química do leite em vacas da raça Holandesa. . Arq. Bras. Med. Vet. Zootec., v.60, n.1, p.19-24, 2008.

HAGNESTAM-NIELSEN, C.; EMANUELSON, U.; BERGLUND, B.; STRANDBERG, E. Relationship between somatic cell count and milk yield in different stages of lactation. Journal of Dairy Science, v.92, n.7, p.3124-33, 2009.

HEINS, B.J.; HANSEN, L.B.; HAZEL, A.R. et al. Jersey $X$ Holstein crossbred cows compared to pure Holstein cows for fertility and survival during the first three lactations. Journal of Dairy Science, v.92, p.567, 2009.

HEINS, B.J.; HANSEN, L.B.; SEYKORA, A.J. et al. Jersey $\times$ Holstein crossbreds compared with pure Holsteins for production, mastitis, and body measurements during the first 3 lactations.

Journal of Dairy Science, v.94, n.1, p.501-506, 2011.

JAMROZIK, J.; SCHAEFFER, L.R. Test-day somatic cell score, fat-to-protein ratio and milk yield as indicator traits for sub-clinical mastitis in dairy cattle. J Anim Breed Genet, v.129, n.1, p.11-9, 2012.
KOECK, A.; MIGLIOR, F.; KELTON, D.F.; SCHENKEL, F.S. Alternative somatic cell count traits to improve mastitis resistance in Canadian Holsteins. J Dairy Sci, v.95, n.1, p.432-9, 2012.

PEREIRA, A.R.; MACHADO, P.F.; SARRÍES, G.A. Contagem de células somáticas e características produtivas de vacas da raça Holandesa em lactação. Scientia Agricola, v.58, n.4, p.649-654, 2001.

PRENDIVILLE, R.; PIERCE, K.M.; BUCKLEY, F. A comparison between Holstein-Friesian and Jersey dairy cows and their $\mathrm{F} 1$ cross with regard to milk yield, somatic cell score, mastitis, and milking characteristics under grazing conditions. Journal of Dairy Science, v.93, n.6, p.27412750, 2010.

SEWALEM, A.; MIGLIOR, F.; KISTEMAKER, G.J.; VAN DOORMAAL, B.J. Analysis of the relationship between somatic cell score and functional longevity in Canadian dairy cattle. Journal of Dairy Science, v.89, n.9, p.36093614, 2006.

TEIXEIRA, N.M.; FREITAS, A.F.; BARRA, R.B. Influência de fatores de meio ambiente na variação mensal da composição e contagem de células somáticas do leite em rebanhos no Estado de Minas Gerais. Arquivo Brasileiro de Medicina Veterinária e Zootecnia, v.55, n.4, p.491-499, 2003. 